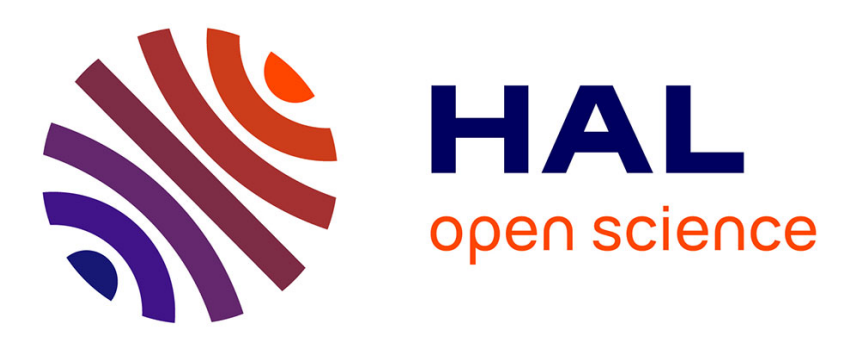

\title{
A Chromium Terephthalate-Based Solid with Unusually Large Pore Volumes and Surface Area
}

G. Férey, C Mellot-Draznieks, C Serre, F Millange, J Dutour, S Surblé, I Margiolaki

\section{- To cite this version:}

G. Férey, C Mellot-Draznieks, C Serre, F Millange, J Dutour, et al.. A Chromium Terephthalate-Based Solid with Unusually Large Pore Volumes and Surface Area. Science, 2005, 309 (5743), pp.2040-2042. 10.1126/science.1116275 . hal-03182295

\section{HAL Id: hal-03182295 https://hal.science/hal-03182295}

Submitted on 26 Mar 2021

HAL is a multi-disciplinary open access archive for the deposit and dissemination of scientific research documents, whether they are published or not. The documents may come from teaching and research institutions in France or abroad, or from public or private research centers.
L'archive ouverte pluridisciplinaire HAL, est destinée au dépôt et à la diffusion de documents scientifiques de niveau recherche, publiés ou non, émanant des établissements d'enseignement et de recherche français ou étrangers, des laboratoires publics ou privés. 


\section{A Chromium Terephthalate-Based Solid with Unusually Large Pore Volumes and Surface Area}

\author{
G. Férey, ${ }^{1,2 *}$ C. Mellot-Draznieks, ${ }^{3}$ C. Serre, ${ }^{1}$ F. Millange, ${ }^{1}$ \\ J. Dutour, ${ }^{1}$ S. Surblé, ${ }^{1}$ I. Margiolaki ${ }^{4}$
}

\begin{abstract}
We combined targeted chemistry and computational design to create a crystal structure for porous chromium terephthalate, MIL-101, with very large pore sizes and surface area. Its zeotype cubic structure has a giant cell volume $(\sim 702,000$ cubic angstroms), a hierarchy of extra-large pore sizes ( $\sim 30$ to 34 angstroms), and a Langmuir surface area for $\mathrm{N}_{2}$ of $\sim 5900 \pm 300$ square meters per gram. Beside the usual properties of porous compounds, this solid has potential as a nanomold for monodisperse nanomaterials, as illustrated here by the incorporation of Keggin polyanions within the cages.
\end{abstract}

Porous materials with large, regular, accessible cages and tunnels are increasingly in demand for applications in catalysis (1), separations (2), sensors, electronics, and gas storage $(3,4)$. Depending on their structure and pore size, these materials allow only molecules of certain shapes and sizes to enter the pores. Furthermore, giant pores may act as nanoreactors, in which the confined volume may generate reactions that do not occur in the bulk material, or as nanomolds for calibrated and monodisperse nanomaterials (5). In this respect, the larger the pores, the wider the range of reactants that can be combined or stored.

However, the design of materials with increasingly large pores carries, especially for metal-organic frameworks, the risk of interpenetration of the skeletons within structures. In addition, although the structural characterization of such solids with large cells is usually possible when single crystals are available, the probability of getting the solutions is known to drastically decrease or even to become zero when the cell dimensions increase too much (6). These problems have restricted the number of discovered porous solids with extralarge pores, of which cloverite, with a cell volume of $\sim 125,000 \AA^{3}$ and pore diameters close to $30 \AA$ (7) is the largest.

We recently developed a strategy to overcome these limitations based on the combination of targeted chemistry and computer simulations. Hybrid porous solids result from the three-dimensional (3D) covalent connection of inorganic clusters and organic moieties that act as linkers, and the first step in our "tailor-

1'Institut Lavoisier, CNRS Unité Mixte de Recherche 8637, Université de Versailles St-Quentin en Yvelines, 45 Avenue des Etats-Unis, 78035 Versailles Cedex, France. ${ }^{2}$ Institut universitaire de France, 103, Boulevard Saint-Michel, 75005 Paris, France. ${ }^{3}$ Royal Institution, 21 Albemarle Street, London W1S 4BS, UK. ${ }^{4}$ European Radiation Synchotron Facility, 38042 Grenoble, France.

*To whom correspondence should be addressed. E-mail: ferey@chimie.uvsq.fr made" approach is to control the nature of the inorganic cluster and the chemical conditions required for its formation and stability in solution (8). In the second step, we use computational strategies, typically our global optimization AASBU (automated assembly of secondary building units) method (9-12), as recently adapted to hybrids (13), or other closely related methods (14). The AASBU method explores how an inorganic cluster and an organic linker, or even predefined hybrid building blocks, may connect in 3D space to form periodic lattices. A virtual library of candidate frameworks is produced, along with their crystallographic features (space group, cell parameters, atomic coordinates) and their simulated x-ray diffraction (XRD) patterns. The comparison of the simulated pattern of each candidate structure with the experimental one identifies the targeted experimental structure, giving direct access to the structural solution without any recourse to single crystals. The final structure is refined with the Rietveld method from powder data, the guest species being localized from Fourier difference maps. While tackling the underlying issue of polymorphism of hybrid materials, our computational approach provides a direct-space tool for solving structures that may be highly complex.

To implement our combined method, we first determined (10) the adequate chemical conditions leading to the existence of trimeric inorganic building blocks, formed by the assembly of three octahedra sharing a $\mu_{3}-\mathrm{O}$ common vertex. Simulations were then performed to combine these inorganic trimers in $3 \mathrm{D}$ space with 1,3,5-benzene tricarboxylate (BTC) through the assembly of a computationally designed hybrid building block. Among the various predicted crystal structures, one candidate exhibited the same powder XRD pattern as the powdered chromium trimesate MIL-100

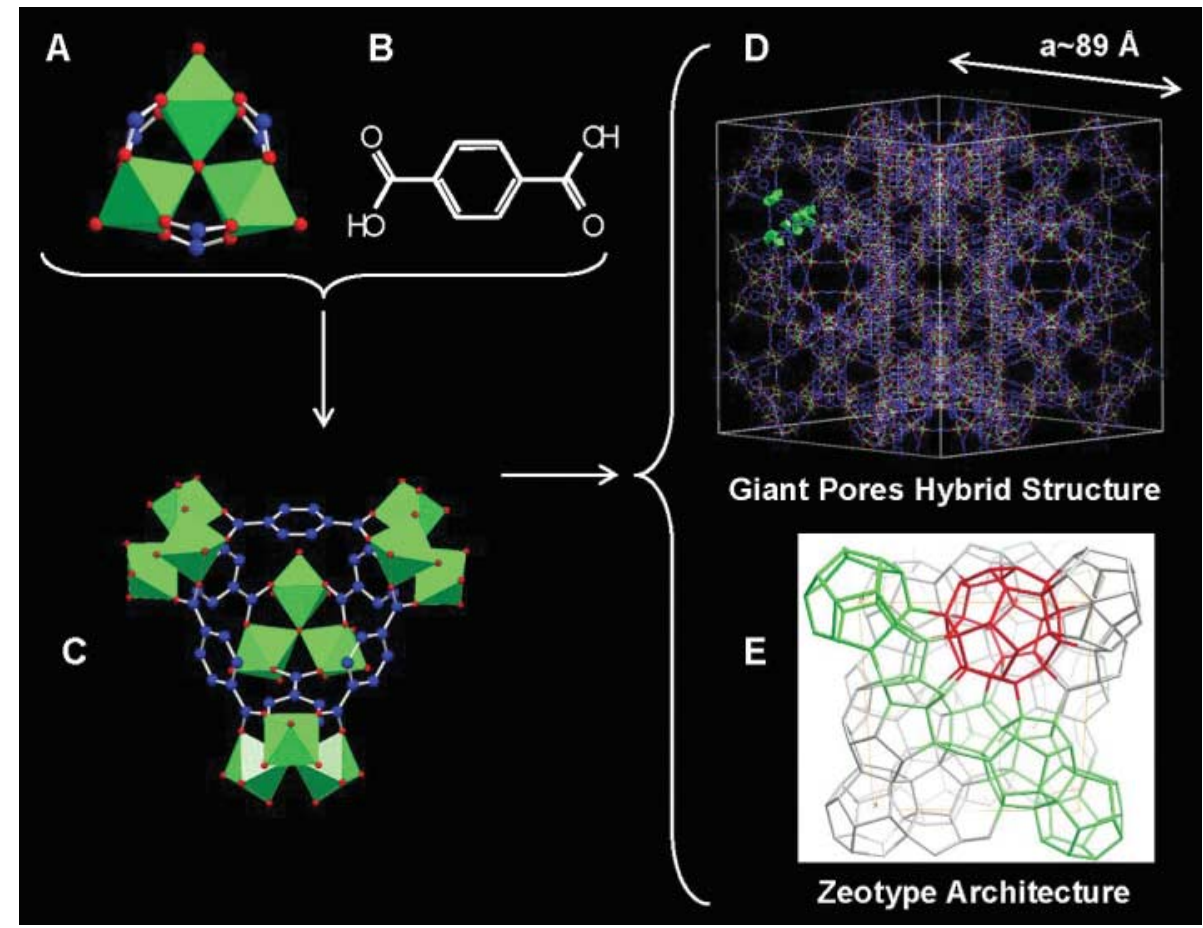

Fig. 1. (A) The computationnally designed trimeric building block chelated by three carboxylic functions. The ST was constructed with (B) terephthalic acid, which lies (C) on the edges of the ST. (D) Ball-and-stick representation of one unit cell, highlighting one ST drawn in a polyhedron mode. (E) Schematic 3D representation of the MTN zeotype architecture (the vertices represent the centers of each ST) with the medium (in green, with 20 tetrahedra) and large (in red with 28 tetrahedra) cages delimited by the vertex sharing of the ST. Chromium octahedra, oxygen, fluorine and carbon atoms are in green, red, and blue, respectively. 
(15) (MIL, Matérial Institut Lavoisier), revealing a giant cell volume $\left(>380,000 \AA^{3}\right)$ and large pore sizes $(\sim 25$ to $29 \AA)$ consistent with the very high surface area measurement $\left(S_{\text {Langmuir }}=\right.$ $3100 \mathrm{~m}^{2} \mathrm{~g}^{-1}$ ). This hybrid crystal structure was then refined from synchrotron powder data, allowing the further localization of the guest moities. MIL-100 showed the feasibility of creating simulation-assisted chemical structures (16). With that adressed, we investigated other carboxylates, here terephthalic acid [1,4-benzene dicarboxylate (1,4-BDC)] combined with similar trimers. Compared to other MOFs (metalorganic frameworks), the resulting solid, MIL101, has the best characteristics in terms of cell dimensions $\left(702,000 \AA^{3}\right)$, pore sizes (29 to $34 \AA$ ), and surface area $\left(5900 \mathrm{~m}^{2} \mathrm{~g}^{-1}\right)$.

The synthesis of MIL-101 consists in the hydrothermal reaction of $\mathrm{H}_{2} \mathrm{BDC}(166 \mathrm{mg}$ at $1 \mathrm{mmol})$ with $\mathrm{Cr}\left(\mathrm{NO}_{3}\right)_{3} \cdot 9 \mathrm{H}_{2} \mathrm{O}(400 \mathrm{mg}$ at 1 $\mathrm{mmol})$, fluorhydric acid $(0.2 \mathrm{ml}$ at $1 \mathrm{mmol})$, and $\mathrm{H}_{2} \mathrm{O}(4.8 \mathrm{ml}$ at $265 \mathrm{mmol})$, for 8 hours at $220^{\circ} \mathrm{C}$. This reaction produced a highly crystallized green powder of the chromium terephthalate with formula $\mathrm{Cr}_{3} \mathrm{~F}\left(\mathrm{H}_{2} \mathrm{O}\right)_{2} \mathrm{O}\left[\left(\mathrm{O}_{2} \mathrm{C}\right)\right.$ $\left.\mathrm{C}_{6} \mathrm{H}_{4}-\left(\mathrm{CO}_{2}\right)\right]_{3} \cdot n \mathrm{H}_{2} \mathrm{O}$ (where $n$ is $\sim 25$ ), based on chemical analysis. The yield based on chromium is $\sim 50 \%$. Analysis of the powder XRD data indicates a cubic cell $(a \sim 89 \AA)$ and a close relationship with the augmented Mobil Thirty-Nine (MTN) zeotype structure of MIL-100 (17). For the simulation process, a candidate hybrid building block, made on the sole basis of its compatibility with the experimental metal:organic ratio of the targeted MIL-

101, was computationally designed as a super tetrahedron (hereafter noted ST) (Fig. 1). It was made from the linkage of 1,4-BDC anions and inorganic trimers that consist of three iron atoms in an octahedral environment with four oxygen atoms of the bidendate dicarboxylates, one $\mu_{3} \mathrm{O}$ atom, and one oxygen atom from the terminal water or fluorine group. Octahedra are related through the $\mu_{3} \mathrm{O}$ oxygen atom to form the trimeric building unit. The four vertices of the ST are occupied by the trimers, and the organic linkers are located at the six edges of the ST. Following our previous strategy (14), the ST building blocks were computationally assembled. The size of the ST requires an expansion of the cubic unit cell (space group $\mathrm{F} d-3 m$ ) to more than $85 \AA$ before the construction process. The connection between the ST was established through vertices to ensure a 3D network of "corner-sharing" super tetrahedra with an augmented MTN zeotype architecture (18) (Fig. 1) and illustrates our concept of scale chemistry (19). Once the structure construction of MIL-101 was computationally completed (74 atoms per asymmetric unit without hydrogen atoms), the model structure of MIL-101 was directly used for full structural refinement with synchrotron data (table S1 and fig. S1) (20). Free water molecules filling the pores were located through successive Fourier differences.

The STs are microporous (with a $\sim 8.6 \AA$ free aperture for the windows), and the resulting framework delimits two types of mesoporous cages filled with guest molecules (Fig. 2). These two cages, which are present

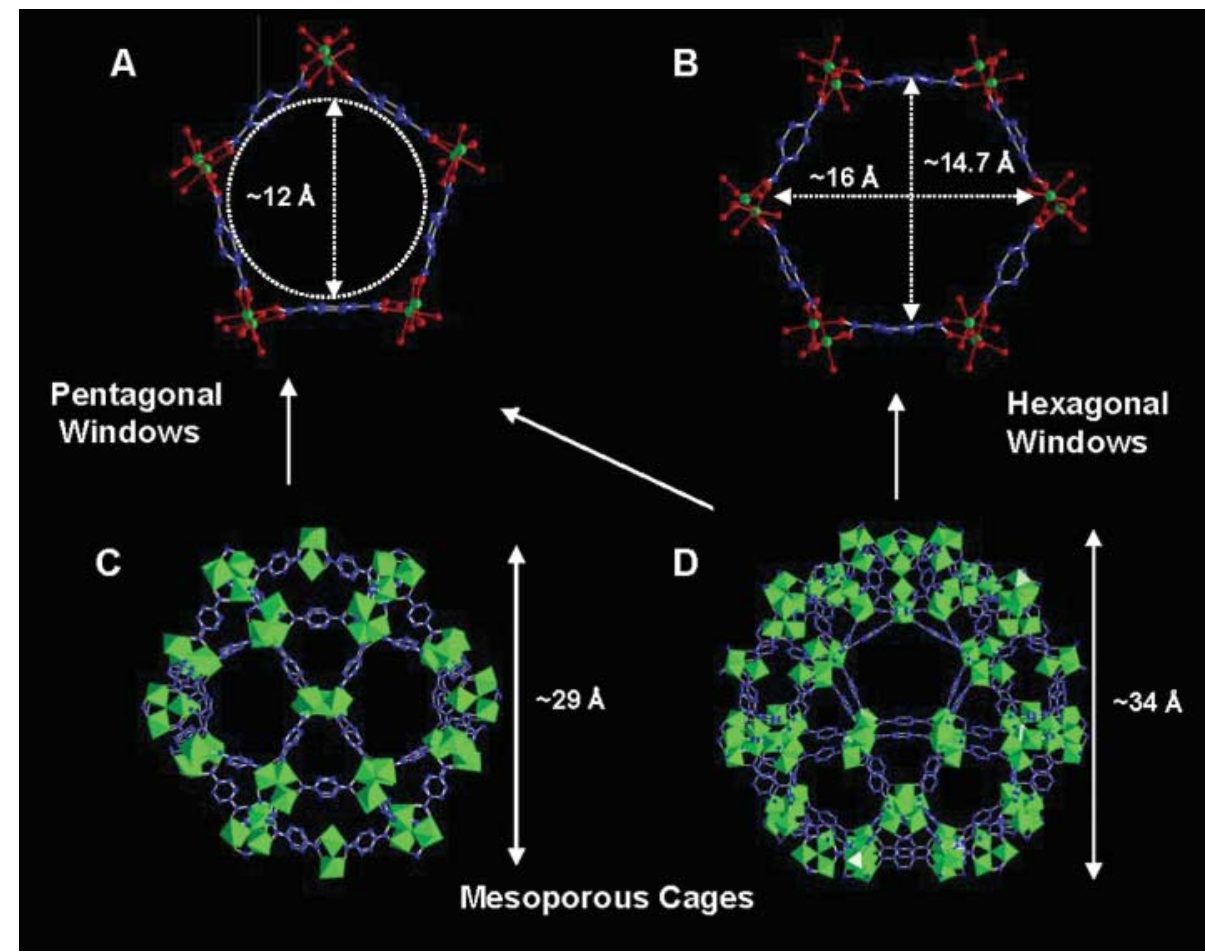

Fig. 2. (A and B) Ball-and-stick view and free dimensions $(\AA)$ of the pentagonal and hexagonal windows. (C and D) Ball-and-stick view of the two cages. Chromium octahedra, oxygen, fluorine and carbon atoms are in green, red, red and blue, respectively. in a $2: 1$ ratio, are delimited by 20 and 28 ST (one by 20 and one by 28) with internal free diameters of $\sim 29 \AA$ and $34 \AA$, respectively (Fig. 2). These values correspond to accessible pore volumes of $\sim 12,700 \AA^{3}$ and $\sim 20,600 \AA^{3}$, respectively. The large windows of both cages make the latter accessible to very large molecules. The smaller cages exhibit pentagonal windows with a free opening of $\sim 12 \AA$, while the larger cages possess both pentagonal and larger hexagonal windows with $\mathrm{a} \sim 14.5 \AA$ by $16 \AA$ free aperture (Fig. 2).

Thermogravimetric analysis in air (fig. S2) revealed that MIL-101 was stable up to $275^{\circ} \mathrm{C}$. X-ray thermodiffractometry showed that the evacuation of the guest molecules did not affect the framework. We also found that MIL-101 exhibited very high uptake of gases. The $\mathrm{N}_{2}$ sorption isotherm on the dehydrated sample (fig. S3A) is of type I with secondary uptakes at $P / P_{0} \sim 0.1$ and at $P / P_{0} \sim$ 0.2 , where $P$ is gas pressure and $P_{0}$ is saturation pressure, characteristic of the presence of the two kinds of microporous windows. Using the Dubinin-Raduskhvich equation, we found a pore volume near $2.0(1) \mathrm{cm}^{3} \mathrm{~g}^{-1}$ for MIL-101. The apparent Brunauer Emmer Teller (BET) and $S_{\text {Langmuir }}$ surface area are larger than 4,100(200) and 5,900(300) $\mathrm{m}^{2} \mathrm{~g}^{-1}$ respectively (Fig. 3). The isotherms are probably overestimating the true internal surface area of MIL-101, but comparisons to be made with related materials are possible. To our knowledge, the highest surface area reported for any crystalline or amorphous solid $\left[4500 \mathrm{~m}^{2} \mathrm{~g}^{-1}\right.$ (Langmuir)], was obtained with MOF-177, a porous hybrid solid (20). The large standard deviations for the surface area of MIL-101 comes both from experimental considerations (such as error on weight measurements and purity of the sample) and from the choice of the points used for the BET or Langmuir calculation (fig. S3B). The as-synthesized MIL-101 solid exhibits a smaller $S_{\text {Langmuir }}$ surface area within the 4500 to $5500 \mathrm{~m}^{2} \mathrm{~g}^{-1}$ range because of the presence of variable amounts of free terephthalic acid outside and within the pores. An activation treatment was thus performed to reach the maximal surface area and pore volume (21).

MIL-101 is stable over months under air atmosphere and was not altered when treated with various organic solvents at room temperature or under solvothermal conditions. These properties, together with high adsorption capacities, make MIL-101 an attractive candidate for the adsorption of gas or large molecules. The very large windows easily allow the introduction of new species into the cages and possible enhanced reactions favored by confinement effects (similar to a pressure) in the cages. Moreover, as soon as introduced nanometric species fill the volume, the fixed dimensions of the pores lead 


\section{REPOR T S}

to monodispersed nanomaterials on the scale of 1 to $3 \mathrm{~nm}$. The possibility of their introduction depends on the fit between their size and the accessible dimensions of the windows of each cage. Large species may therefore occupy only the large cages $\left(\sim 20,600 \AA^{3}\right)$ while leaving space for other species with different properties in the small cages $\left(\sim 12,700 \AA^{3}\right)$. Such a selective placement of guests might lead to hitherto unknown assemblies of monodisperse multifunctional nanomaterials and the possibility of structural characterization of these nano-objects when the host structure is not affected by the introduction of species.

To illustrate this idea, we explored the incorporation of Keggin polyanions in MIL-101. Such incorporation has been achieved previously through the encapsulation of a molybdenum Keggin anion in a metal-oxygen system (22). The $\mathrm{K}_{7} \mathrm{PW}_{11} \mathrm{O}_{40} \cdot n \mathrm{H}_{2} \mathrm{O}$ salt was selected because of its low acidity, the presence of a ${ }^{31} \mathrm{P}$ nuclear magnetic resonance (NMR) nucleus for NMR characterization, and finally its size (van der Waals radius, $\sim 13.1 \AA$ ), which rules out the diffusion of Keggin ions into the small cages. A powdered sample of MIL-101 was placed in an aqueous solution

of the Keggin salt for 2 hours. To probe the presence of the polynanion within the pores, the resulting MIL-101-Keggin solid was analyzed by thermal gravimetric analysis (TGA), $\mathrm{N}_{2}$ sorption measurement, $\mathrm{XRD},{ }^{31} \mathrm{P}$ solid state NMR (Fig. 4), and infrared spectroscopy (fig. S3). All of these techniques confirmed the presence of a large amount of the Keggin ions within the pores: a strong decrease in the weight losses [TGA (fig. S2)] and surface areas $\left[S_{\text {Langmuir }} \sim 3,750(250) \mathrm{m}^{2} \mathrm{~g}^{-1}\right.$ instead of 5,900(300) $\mathrm{m}^{2} \mathrm{~g}^{-1}$ for MIL-101 (fig. S3C)] due to the higher density of the Keggan moieties compared to MIL-101. We observed significant changes in XRD peak intensities but not of the Bragg peak positions (fig. S4). Infrared spectroscopy confirmed the presence of the polyanions within the pores of MIL-101 (fig. S5). ${ }^{31} \mathrm{P}$ NMR also indicated one single peak at about-12.2(1) parts per million ( $\mathrm{ppm}$ ), confirming that the integrity of the Keggin structure was retained within the pores of MIL-101 (fig. S6).

Quantitative analysis (17) also gave an estimation of $\sim 0.05$ Keggin anions per chromium. Considering the size of the $\mathrm{K}_{7} \mathrm{PW}_{11} \mathrm{O}_{40}$ ion, we assumed that the polyanions could diffuse into the largest cages only, which would

Fig. 3. Nitrogen gas sorption isotherm at $78 \mathrm{~K}$ for MIL-101. P/P is the ratio of gas pressure $(P)$ to saturation pressure $\left(P_{0}=750\right.$ torr $)$.

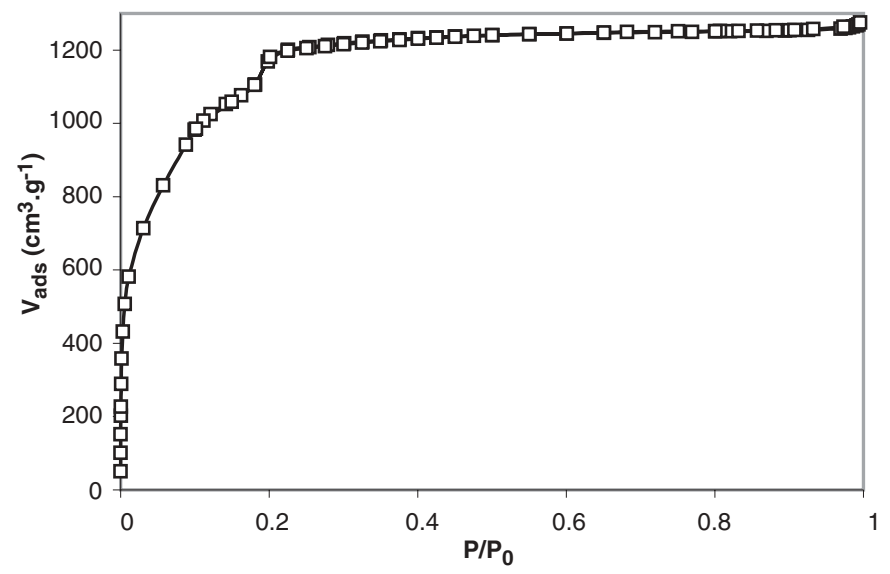

A

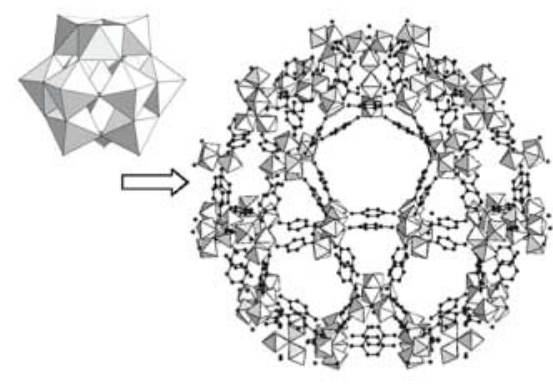

Fig. 4. (A) Schematic view of the insertion of Keggin anions within the largest pore of MIL-101. (B) XRD of MIL-101 (1) and MIL101(Keggin) (2). $\theta$, in degrees. (C) TGA of MIL-101 (1) and MIL-101(Keggin) (2). T, temperature (K). (D) Nitrogen sorption-desorption isotherms at $78 \mathrm{~K}$ of MIL-101 (1) and MIL-101(Keggin) (2). $\mathrm{V}_{\text {ads }}$, volume adsorbed in $\mathrm{cm}^{3} \mathrm{~g}^{-1}$. (E) ${ }^{31} \mathrm{P}$ solid-state NMR spectra of the Keggin salt and MIL-101(Keggin). $\delta$, chemical shift in ppm. allow about five highly charged Keggin moities per large cage (Keggin per cage, $\sim 5.3$ ). Because the volume of a $\mathrm{PW}_{11} \mathrm{O}_{40}{ }^{7-}$ anion is nearly $2250 \mathrm{~A}^{3}$, five Keggin ions represent $\sim 10,100 \mathrm{~A}^{3}$ in volume, which is lower than the $\sim 20,600 \mathrm{~A}^{3}$ volume of a large cage. The residual volume is probably occupied by cations and water molecules. This successful incorporation of Keggin anions in large amounts strongly suggests that MIL-101, a crystallized hybrid solid with a periodical and calibrated porosity, is an excellent candidate for the introduction of gas (23) nano-objects in a regular and monodisperse mode with specific physical properties (24) or for drug delivery (25).

\section{References and Notes}

1. J. S. Seo et al., Nature 404, 982 (2000).

2. F. Schüth et al., Handbook of Porous Solids (WileyVCH, Weinheim, Germany, 2002), vol. 3, p. 563.

3. J. L. C. Rosell et al., J. Am. Chem. Soc. 126, 5666 (2004).

4. G. Férey et al., Chem. Commun. 2003, 2276 (2003).

5. B. H. Hong et al., Science 294, 348 (2001).

6. R. S. Batten et al., Angew. Chem. Int. Ed. Engl. 37, 1460 (1998)

7. M. Estermann, L. B. McCusker, C. Baerlocher, A. Merrouche, H. Kessler, Nature 352, 320 (1991).

8. C. Serre et al., Angew. Chem. Int. Ed. Engl. 43, 6286 (2004).

9. S. Girard et al., Stud. Surf. Sci. Catal. 135, 254 (2001).

10. C. Mellot-Draznieks et al., J. Am. Chem. Soc. 124, 15326 (2002).

11. C. Mellot-Draznieks et al., Chem. Eur. J. 8, 4102 (2002).

12. C. Mellot-Draznieks et al., Angew. Chem. Int. Ed. Engl. 39, 2271 (2000).

13. C. Mellot-Draznieks et al., Angew. Chem. Int. Ed. Engl. 43, 6290 (2004)

14. C. Mellot-Draznieks et al., Z. Anorg. Allg. Chem. 630 , 2599 (2004).

15. G. Férey et al., Angew. Chem. Int. Ed. Engl. 43, 6296 (2004).

16. G. Férey et al., Acc. Chem. Res. 38, 217 (2005).

17. Materials and methods are available as supporting material on Science Online.

18. Available at www.iza-structure.org/databases.

19. G. Férey, J. Solid State Chem. 152, 37 (2000)

20. H. K. Chae et al., Nature 427, 523 (2004).

21. Materials and methods are available as supporting material on Science Online.

22. A. Muller et al., Angew. Chem. Int. Ed. Engl. 39, 3414 (2000).

23. Initial hydrogen storage measurements were $\sim 0.45$ and 3.75 weight percent at $293 \mathrm{~K}$ and $77 \mathrm{~K}$, respectively, at $2 \mathrm{MPa}$. The values at $77 \mathrm{~K}$ seem to be the highest for MOFs after the contestation of previous results (3).

24. Initial introduction of semiconducting ZnS nanoparticles in the pores of MIL-101 was successfully achieved with a $\mathrm{ZnS} / \mathrm{Cr}$ ratio close to 0.5 .

25. Incorporation of ibuprofen within MIL-101 has been achieved in large amounts ( $\sim \mathrm{g}$ of drug per gram of MIL-101) with a total release of the drug within a few days.

26. We thank F. Taulelle and M. Haouas for collecting solid state NMR, M. Latroche for hydrogen sorption measurements, P. Mialane for providing the Keggin salt and for helpful discussions, S. Floquet and E. Cadot for helpful discussion about the introduction of $\mathrm{ZnS}$ nanoparticles, and P. Horcajada and M. Vallet-Regi for the drug incorporation study.

\section{Supporting Online Material}

www.sciencemag.org/cgi/content/full/309/5743/2040/ DC1

Materials and Methods

Figs. S1 to S6

Table S1

References and Notes

17 June 2005; accepted 16 August 2005

10.1126/science. 1116275 
post date 18 November 2005

Reports: "A chromium terephthalate-based solid with unusually large pore volumes and surface area" by G. Férey et al. (23 Sept. 2005, p. 2040). The crystal structure deposition number for MIL-101 was omitted; the CSD number is 415697 . There were errors in note (23); it should read "Initial hydrogen storage measurement was 4.5 weight percent at $77 \mathrm{~K}$ at $3 \mathrm{MPa}$. This value seems to be the highest for MOFs after the contestation of previous results (3)." Finally, the last sentence of the Fig. 1 legend should read "Chromium octahedra, oxygen, fluorine, and carbon atoms are in green, red, red, and blue, respectively." 
